\title{
Relationships Between Housing and Food Insecurity, Frequent Mental Distress, and Insufficient Sleep Among Adults in 12 US States, 2009
}

Yong Liu, MD, MS; Rashid S. Njai, PhD, MPH; Kurt J. Greenlund, PhD; Daniel P. Chapman, PhD, MSc; Janet B. Croft, PhD

Suggested citation for this article: Liu Y, Njai RS, Greenlund KJ, Chapman DP, Croft JB. Relationships Between Housing and Food Insecurity, Frequent Mental Distress, and Insufficient Sleep Among Adults in 12 US States, 2009. Prev Chronic Dis 2014;11:130334. DOI: http://dx.doi.org/10.5888/pcd11.130334国.

PEER REVIEWED

\section{Abstract}

\section{Introduction}

Housing insecurity and food insecurity may be psychological stressors associated with insufficient sleep. Frequent mental distress may mediate the relationships between these variables. The objective of this study was to examine the relationships between housing insecurity and food insecurity, frequent mental distress, and insufficient sleep.

\section{Methods}

We analyzed data from the 2009 Behavioral Risk Factor Surveillance System in 12 states. Housing insecurity and food insecurity were defined as being worried or stressed "sometimes," "usually," or "always" during the previous 12 months about having enough money to pay rent or mortgage or to buy nutritious meals.

\section{Results}

Of 68,111 respondents, 26.4\% reported frequent insufficient sleep, $28.5 \%$ reported housing insecurity, 19.3\% reported food insecurity, and $10.8 \%$ reported frequent mental distress. The prevalence of frequent insufficient sleep was significantly greater among those who reported housing insecurity (37.7\% vs $21.6 \%$ ) or food insecurity ( $41.1 \%$ vs 22.9\%) than among those who did not. The prevalence of frequent mental distress was also significantly greater among those reporting housing insecurity (20.1\% vs $6.8 \%$ ) and food insecurity (23.5\% vs $7.7 \%$ ) than those who did not. The association between housing insecurity or food insecurity and frequent insufficient sleep remained significant after adjustment for other sociodemographic variables and frequent mental distress.

\section{Conclusion}

Sleep health and mental health are embedded in the social context. Research is needed to assess whether interventions that reduce housing insecurity and food insecurity will also improve sleep health and mental health.

\section{Introduction}

Healthy People 2020 and the World Health Organization maintain that social determinants of health, including social, economic, and physical environments, shape people's opportunities to achieve optimal health $(1,2)$. Furthermore, the 5 -tier health impact pyramid suggests that interventions related to the improvement of socioeconomic factors may have the greatest potential impact to change the social context to enable an individual's default decisions to be healthy (3). Housing insecurity and food insecurity have been identified as 2 important social determinants of health $(4,5)$. The definitions of housing insecurity vary and include having high housing costs relative to household income, living in environments of poor quality and unstable neighborhoods, living in overcrowded housing, or being homeless (6). In 2010, more than a quarter of US households (20.2 million households) paid more than $50 \%$ of their incomes for housing (7). Food insecurity can be defined as uncertainty about one's ability to access safe and nutritious foods because of restricted financial resources (8). Nearly 15\% of US households (approximately 48.8 million Americans) were food insecure at some time during 2010; 10.5\% of US households were food insecure during 2000 (9). Research 
suggests that food insecurity is associated with the consumption of more high-energy-dense foods that may lead to weight gain, diabetes, and poor physical health $(10,11)$. Studies also indicate that food insecurity is associated with psychological distress, anxiety, and depression among low-income women and children (12,13). Psychological distress may, in turn, adversely affect people's physical health, mental health, and sleep (14).

Emerging data suggest that insufficient sleep is associated with obesity, diabetes, cardiovascular disease, stroke, high blood pressure, arthritis, asthma, anxiety, and depression (15-20); the rate of poor sleep is higher among women than men and is correlated with low household income, poverty, and unemployment (21-23). In 2008, 37.9\% of US adults reported 14 days or more of insufficient sleep (24). Few studies have addressed the relationship between housing insecurity and insufficient sleep (21,22). The Behavioral Risk Factor Surveillance System (BRFSS), the largest telephone surveillance system in the world, recently began collecting data on insufficient sleep, defined as the number of days that the respondent felt that he or she did not get enough rest or sleep in the previous 30 days. The survey also began collection data on housing insecurity and food insecurity among US adult respondents (25). Frequent mental distress ( $\geq 14$ days of mental distress during the previous 30 days) is a reliable indicator of psychological distress (26) and is also highly associated with insufficient sleep (18-22). The objective of this study was to assess the relationships between housing insecurity, food insecurity, frequent mental distress, and insufficient sleep.

\section{Methods}

The BRFSS, a state-based, random-digit-dialed telephone survey of noninstitutionalized, civilian US adults aged 18 or older, consists of a core set of questions on public health issues that are asked in all states and optional modules that states may elect to include. In 2009, an optional module on social context, which included questions on housing insecurity and food insecurity, was administered in 12 states (Alabama, Arkansas, California, Hawaii, Illinois, Kansas, Louisiana, Nebraska, New Mexico, Oklahoma, South Carolina, and Wisconsin). Data from 68,111 (90.7\%) of 75,103 respondents to this module were analyzed after excluding those who did not respond to questions about sleep $(\mathrm{n}=$ $1,320)$ and housing insecurity or food insecurity $(\mathrm{n}=5,672)$. The response rate in these 12 states ranged from $42.8 \%$ to $66.9 \%$ (median, $58.2 \%$ ) (27).

\section{Variables}

The outcome variable, perceived insufficient sleep, was obtained from self-reported responses to the core question "During the past 30 days, for about how many days have you felt you did not get enough rest or sleep?" Frequent insufficient sleep, defined as not getting enough rest or sleep 14 days or more in the previous 30 days, was used in this analysis. Research has shown significant relationships between insufficient sleep, chronic diseases, obesity, and other risk factors when insufficient sleep was defined as 14 days or more in the previous 30 days without sufficient sleep (1520).

Independent variables in this study were housing insecurity and food insecurity. The social context module included the questions, "How often in the past 12 months would you say you were worried or stressed about having enough money" to pay your rent or mortgage (housing insecurity) or to buy nutritious meals (food insecurity)? Response options to both questions were "never," "rarely," "sometimes," "usually," and "always." We classified respondents as having housing insecurity or food insecurity if they reported that they "always," or "usually," or "sometimes" felt worried or stressed.

Covariates in this study were age (18-44 y, 45-64 y, $\geq 65$ y), sex, race/ethnicity (non-Hispanic white, non-Hispanic black, Hispanic, and other non-Hispanic), and years of education (<12 y, $12 \mathrm{y}$ or high school equivalency diploma, or $>12$ y). We examined a potential mediation variable, frequent mental distress, defined as the respondents reporting 14 days or more in the previous 30 days that they did not feel their mental health was good. Mental health is defined by the BRFSS question as including "stress, depression, and problems with emotions." Frequent mental distress has been analyzed as an indicator of prolonged mental distress and is associated with insufficient sleep and sleep duration $(18,20,28)$.

\section{Statistical analysis}

First, we generated the distribution of the study population by the selected characteristics. Second, we conducted bivariate analyses of frequent insufficient sleep, frequent mental distress, housing insecurity, and food insecurity associated with the selected characteristics. Third, the adjusted prevalence ratios (PRs) and 95\% confidence intervals (CIs) characterizing the relationships of frequent insufficient sleep with housing insecurity and food insecurity were obtained from separate multivariate logistic regression models after controlling for age, sex, race/ethnicity, and educational attainment. We conducted further analyses to examine whether frequent mental distress mediates these relationships. The magnitude and significance of the mediating effect was assessed by measuring the percentage change in the PR between a model with a specific mediator and a model without it [(PRno mediator - PRwith a mediator)/(PRno mediator - 1)] × 100 (29,30). To be conservative, we noted a change of $20 \%$ or more in the PR (30) only when housing insecurity or food insecurity was significantly associated with both frequent mental distress and 
frequent insufficient sleep and frequent mental distress was also significantly associated with frequent insufficient sleep (31). We considered frequent mental distress to have a partial mediating effect on the relationship between housing or food insecurity and frequent insufficient sleep if the relationship remained significant after frequent mental distress was added to the model and a complete mediating effect if the relationship was no longer significant after frequent mental distress was added to the model (31). SAS-callable SUDAAN software was used to account for the complex sampling design (32). The significance level was denoted at $\mathrm{P}<.05$.

\section{Results}

Of the 68,111 survey respondents in this study, $50.8 \%$ were aged 45 or older, $62.2 \%$ were non-Hispanic white, $61.9 \%$ had more than 12 years education, $28.5 \%$ reported housing insecurity and $19.3 \%$ reported food insecurity during the previous 12 months, and $10.8 \%$ reported frequent mental distress and $26.4 \%$ reported frequent insufficient sleep during the previous 30 days (Table 1). In addition, a significantly higher percentage of non-Hispanic blacks, Hispanics, and other non-Hispanics than non-Hispanic whites reported food insecurity $(\mathrm{P}<.001)$ and housing insecurity $(\mathrm{P}$ $<$.001) (Figure). A significantly higher percentage of respondents who had 12 years or less of education reported food insecurity $(\mathrm{P}<.001)$ and housing insecurity $(\mathrm{P}<$.001) than those with more than 12 years of education.

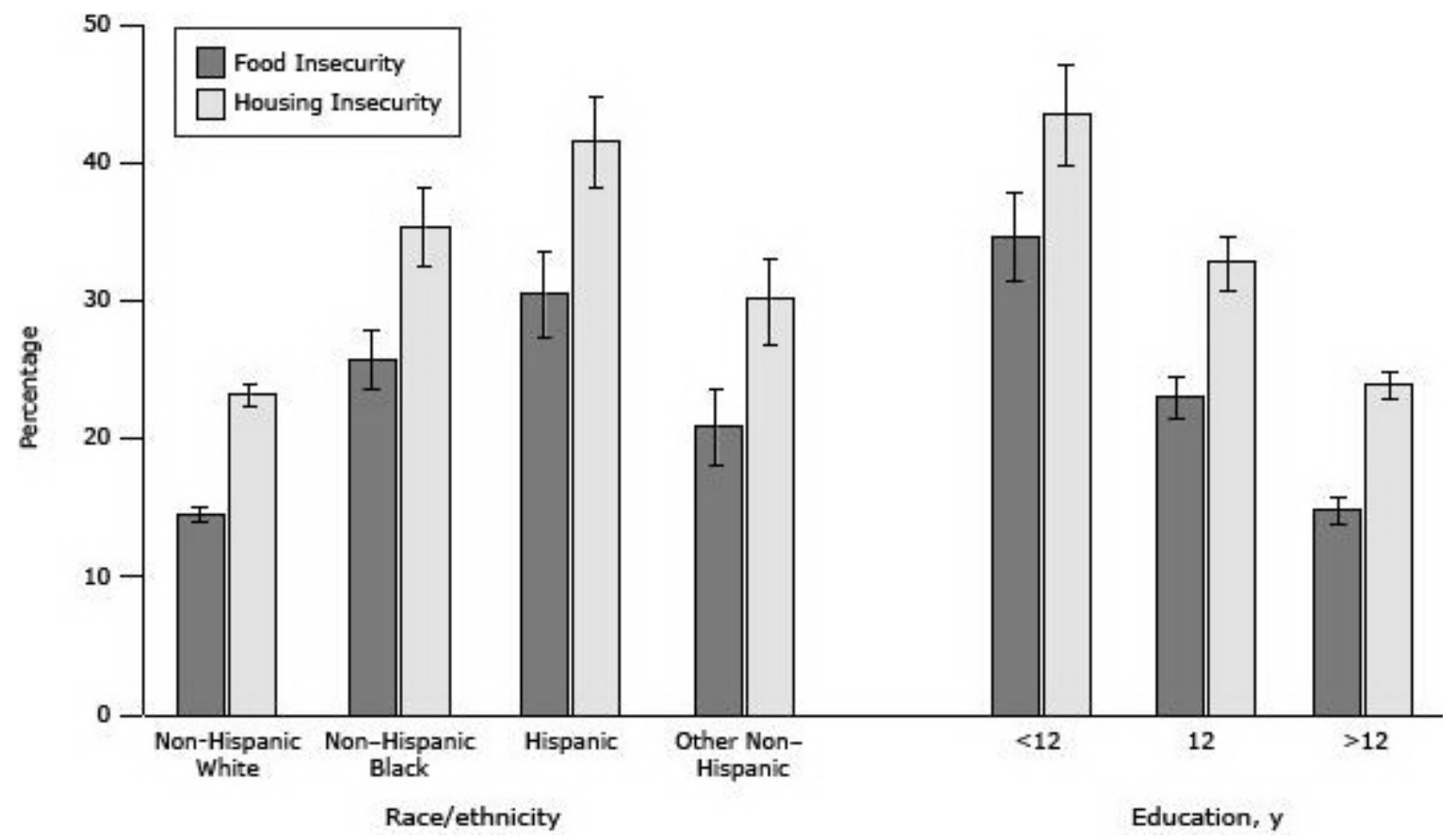

Figure. Percentage of housing insecurity and food insecurity by race/ethnicity and educational levels among adults aged 18 or older in 12 states, Behavioral Risk Factor Surveillance System, 2009. Error bars indicate 95\% confidence intervals. [A tabular version of this figure is also available.]

Bivariate analyses (Table 2) showed that the prevalences for both frequent insufficient sleep and frequent mental distress were significantly higher among women than among men and among people younger than 65 than among those aged 65 or older $(\mathrm{P}<$.001). A significantly greater percentage of non-Hispanic blacks reported frequent insufficient sleep $(\mathrm{P}=.02)$ and frequent mental distress $(\mathrm{P}<.001)$ than non-Hispanic whites. The percentage of Hispanics reporting frequent insufficient sleep was similar to that reported by non-Hispanic whites $(\mathrm{P}=.17)$, but a significantly greater percentage of Hispanics reported frequent mental distress $(\mathrm{P}<.001)$. The prevalence of frequent insufficient sleep did not differ significantly by years of education, but the prevalence of frequent mental distress was negatively associated with years of education $(\mathrm{P}<.001)$. The unadjusted prevalence of frequent insufficient sleep was significantly higher among respondents who reported either housing insecurity or food insecurity than among those who did not $(\mathrm{P}<.001)$. Respondents who reported either housing insecurity or food insecurity were about 3 times as likely to report frequent mental distress than were those who did not, and those who reported frequent mental distress were more than twice as likely to report frequent insufficient sleep as those who did not (59.7\% vs $22.3 \%$ ).

Unadjusted results showed that respondents who reported housing insecurity or food insecurity were each more than $70 \%$ more likely to report frequent insufficient sleep than those who did not report the insecurity (Table 3, Model 1). Housing insecurity and food insecurity remained significantly associated with frequent insufficient sleep after adjustment for sociodemographic covariates for housing insecurity (PR = 1.67; 95\% CI, 1.55-1.79) and for food insecurity ( $\mathrm{PR}=1.75 ; 95 \% \mathrm{CI}, 1.62-1.88$ ) (Table 3, Model 2). Although further adjustment for respondents' frequent 
mental distress status reduced the magnitude of the relationship by 27\% (Table3, Model 3), both housing insecurity and food insecurity remained significantly associated with frequent insufficient sleep, suggesting that frequent mental distress was only a partial mediator of the relationships of these social context variables with insufficient sleep.

\section{Discussion}

Our results demonstrated that both housing insecurity and food insecurity were associated with frequent insufficient sleep among US adults in 12 states. This positive relationship was modestly attenuated but not completely explained by frequent mental distress. Although the mechanisms underlying the association are not clear, one potential explanation is that stress caused by housing insecurity or food insecurity could lead to prolonged psychological distress or depressive symptoms (13,33-35). Previous studies have also shown that housing insecurity, particularly crowding and multiple relocations, were associated with psychological distress, poor health, and developmental risk among children $(33,34)$, and food insecurity was highly associated with mental distress among women $(13,35)$ and school-aged children (12) even after adjustments for sociodemographic characteristics. In addition, poor housing conditions may also be related to poor sleep through concerns about personal safety, exposure to higher noise levels, and inadequate heating or cooling $(36,37)$.

Other studies reported that low levels of food security were significantly associated with short sleep duration and suggested that the significant relationship might be due to racial/ethnic minority status and low socioeconomic position $(21,22)$, findings that are also consistent with ours. Furthermore, hunger may acutely affect the ability to sleep well. Educational and racial/ethnic disparities in these social contexts may also play an important role in perceived insufficient sleep and frequent mental distress.

Chronic stress or worry related to poor housing and poor nutrition may interact with endocrine systems such as the sympathoadrenal medullary and the hypothalamo-pituitary-adrenocortical systems and are associated with elevated levels of cortisol, adrenocorticotropic hormone (ACTH), and corticotropin-releasing hormone (CRH). Research indicated that an elevated level of cortisol was highly associated with frequent microarousals (38). In addition, elevated ACTH levels could increase the frequency of morning awakening (39). Furthermore, the stages of slow-wave sleep and rapid eye movements in the sleep cycle could be reduced by excessive release of CRH (40). These physiological changes may cause sleep disturbances with increased cognitive arousal or cortical arousal or both (41).

Our results were consistent with previous studies in which either "housing instability" (definitions of which have included frequent moves, difficulty paying rent, spending more than half of household income on housing, being evicted, or living in overcrowded conditions) or "food insufficiency" (respondents reported that their family sometimes or often did not get enough food to eat) was used to assess the relationship with mental health $(12,13,33)$. As in these earlier cross-sectional studies, which examined the relationship of each social context with frequent insufficient sleep, we cannot assess causation.

Although this is the largest study to date to address the relationship between housing insecurity and food insecurity and insufficient sleep among US adults, it has several limitations. First, because it was a cross-sectional study, we cannot establish causation. Second, because our results are based on the analysis of information provided by BRFSS in only 12 states and BRFSS does not include people residing in institutions such as nursing homes and prisons, our results are not generalizable to the entire US adult population. Third, the dichotomous measures of housing insecurity and food insecurity used in this study were each derived from responses to a single survey question on respondents' confidence in their financial capacity to acquire adequate housing and food and therefore did not reflect all respects of housing insecurity and food insecurity. For example, the measure of housing insecurity did not address whether respondents resided in housing of poor quality, in overcrowded housing, or in unstable neighborhoods (6), and the measure of food insecurity did not reflect the extent to which respondents experienced hunger (9). However, the influence of the different definitions of housing insecurity and food insecurity on our results may be limited given the findings from previous studies that are consistent with ours (9,33,34). In addition, frequent insufficient sleep is a subjective measure of sleep health and was not corroborated by polysomnography. However, frequent insufficient sleep may partly reflect some sleep problems such as obstructive sleep apnea and is highly related to sleep duration (20). Efforts are needed to address the mediating role of other social determinants such as marriage, income, employment, accessibility of health services, and geographic variation in social context in the relationship of housing insecurity and food insecurity with poor sleep $(22,23,42)$. Finally, our results could have been influenced by residual variations because other cofounders were not taken into account.

Fundamental societal transformations may be required to achieve social and economic changes that affect health (3). Potential improvements in housing and access to healthy food include community-level projects to provide environmentally healthful and safe housing for low-income families, food subsidy programs, and educational technology programs to enable low-income individuals to re-enter the workforce in new careers. 
In summary, our findings, which are based on general-population data, add to a growing body of evidence that shows housing insecurity and food insecurity are associated with psychological distress and insufficient sleep. Our findings are consistent with previous findings showing that stress related to housing insecurity and food insecurity may sustain and adversely affect sleep and precipitate long-term adverse consequences to physical and mental health. Furthermore, our findings support the idea that sleep health and mental health are embedded in the social context. Research is needed to assess whether interventions that reduce housing insecurity and food insecurity will also improve those outcomes.

\section{Acknowledgments}

This research received no specific grant from any funding agency in the public, commercial, or nonprofit sectors.

\section{Author Information}

Corresponding Author: Yong Liu, MD, MS, Epidemiology and Surveillance Branch, Division of Population Health, Centers for Disease Control and Prevention, 4770 Buford Hwy NE, MS F-78, Atlanta, GA 30341. Telephone: 770-4885528. E-mail:ikd8@cdc.gov.

Author Affiliations: Rashid S. Njai, Kurt J. Greenlund, Daniel P. Chapman, Janet B. Croft, Centers for Disease Control and Prevention, Atlanta, Georgia.

\section{References}

1. Commission on Social Determinants of Health (CSDH). Closing the gap in a generation: health equity through action on the social determinants of health. Final report of the Commission on Social Determinants of Health. Geneva (CH): World Health Organization; 2008.

http://www.who.int/social_determinants/thecommission/finalreport/en/index.html. Accessed January 3, 2013.

2. Secretary's Advisory Committee on Health Promotion and Disease Prevention Objectives for 2020, Healthy People 2020: Social determinants of health.

http://www.healthypeople.gov/2020/topicsobjectives2020/overview.aspx?topicid=39. Accessed January 3, 2013.

3. Frieden TR. A framework for public health action: the health impact pyramid. Am J Public Health 2010;100 (4):590-5. CrossRef 圈 PubMed 圈

4. Kushel MB, Gupta R, Gee L, Haas JS. Housing instability and food insecurity as barriers to health care among low

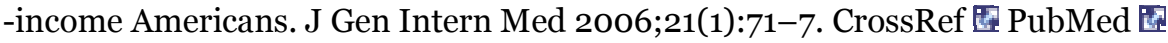

5. Satcher D. Include a social determinants of health approach to reduce health inequities. Public Health Rep 2010;125(Suppl 4):6-7. PubMed 圈

6. Johnson A, Meckstroth A. Ancillary services to support welfare to work. Washington (DC): US Dept. of Health and Human Services; 1998. http://aspe.hhs.gov/hsp/isp/ancillary/front.htm. Accessed January 14, 2013.

7. Alexander B, Apgar W, Baker K, Baldwin P, Belsky E, Carliner M, et al. The state of nation's housing 2012. Cambridge (MA): Joint Center for Housing Studies of Harvard University; 2012. http://www.jchs.harvard.edu. Accessed March 12, 2013.

8. Core indicators of nutritional state for difficult-to-sample population. J Nutr 1990;120(Suppl 11):1559-60o. PubMed 圈

9. Coleman-Jensen A, Nord M, Andrews M, Carlson S. Household food security in the United States in 2010. Economic Research Report No. 125. Washington (DC): US Department of Agriculture, Economic Research Service; 2011.

10. Jyoti DF, Frongillo EA, Jones SJ. Food insecurity affects school children's academics performance, weight gain, and social skills. J Nutr 2005;135(12):2831-9. PubMed 国

11. Gucciardi E, Vogt JA, Demelo M, Stewart DE. Exploration of the relationship between household food insecurity and diabetes in Canada. Diabetes Care 2009;32(12):2218-24. CrossRef 国 PubMed 圈

12. Alaimo K, Olson CM, Frongillo EA. Food insufficiency and American school-aged children's cognitive academic and psychological development. Pediatrics 2001;108(1):44-53. PubMed 园

13. Siefert K, Heflin CM, Corcoran ME, Williams DR. Food insufficiency and the physical and mental health of lowincome women. Women Health 2001;32(1-2):159-77. CrossRef 国 PubMed 圈

14. Sateia MJ. Updates of sleep and psychiatric disorders. Chest 2009;135(5):1370-9. CrossRef 8 PubMed 娄

15. Vishnu A, Shankar A, Kalidindi S. Examination of the association between insufficient sleep and cardiovascular disease and diabetes by race/ethnicity. Int J Endocrinol 2011;2011:789358. CrossRef 圈 PubMed 圈 
16. Sabanayagam C, Shankar A. The association between active smoking, smokeless tobacco, second-hand smoke exposure and insufficient sleep. Sleep Med 2011;12(1):7-11. CrossRef 国 PubMed 圈

17. Shankar A, Syamala S, Kalidindi S. Insufficient rest or sleep and its relation to cardiovascular disease, diabetes and obesity in a national, multiethnic sample. PLoS ONE 2010;5(11):e14189. CrossRef 国 PubMed 国

18. Strine TW, Chapman DP. Association of frequent sleep insufficiency with health-related quality of life and health behaviors. Sleep Med 2005;6(1):23-7. CrossRef 圈 PubMed 圈

19. Wheaton AG, Perry GS, Chapman DP, McKnight-Eily LR, Presley-Cantrell LR, Croft JB. Relationship between body mass index and perceived insufficient sleep among US adults: an analysis of 2008 BRFSS data. BMC Public Health 2011;11:295-302. CrossRef 圈 PubMed 圈

20. Liu Y, Croft JB, Wheaton AG, Perry GS, Chapman DP, Strine TW, et al. Association between perceived insufficient sleep, frequent mental distress, obesity and chronic disease among US adults, 2009 Behavioral Risk Factor Surveillance System. BMC Public Health 2013;13:84. CrossRef 圈 PubMed 圈

21. Grandner MA, Ruiter Petrov ME, Jackson N, Rattanaumpawan P, Patel NP. Sleep symptoms, race/ethnicity, and socioeconomic position. J Clin Sleep Med 2013;9(9):897-905. PubMed 圈

22. Whinnery J, Jackson N, Rattanaumpawan P, Grandner MA. Sleep symptoms, race/ethnicity, and socioeconomic position. Sleep 2013. http://www.journalsleep.org/AcceptedPapers/SP-225-13.pdf. Accessed November 14, 2013.

23. Patel NP, Grandner MA, Xie D, Branas CC, Gooberatne N. "Sleep disparity" in the population: poor sleep quality is strongly associated with poverty and ethnicity. BMC Public Health 2010;10:475-85. CrossRef 国 PubMed 国

24. Centers for Disease Control and Prevention. Perceived insufficient rest or sleep among adults - United States, 2008. MMWR Morb Mortal Wkly Rep 2009;58(42):1175-9. PubMed 圈

25. Centers for Disease Control and Prevention. Perceived insufficient rest or sleep - four states, 2006. MMWR Morb Mortal Wkly Rep 2008;57(8):200-3. PubMed 圈

26. Andresen EM, Catlin TK, Wyrwich KW, Jackson-Thompson J. Retest reliability of surveillance questions on health related quality of life. J Epidemiol Community Health 2003;57(5):339-43. CrossRef 因 PubMed 因

27. Centers for Disease Control and Prevention. Behavior Risk Factor Surveillance System 2009 summary data quality report (version no. 1, revised February 18, 2011).

ftp://ftp.cdc.gov/pub/Data/Brfss/2009_Summary_Data_Quality_Report.pdf. Accessed January 14, 2013.

28. Strine TW, Balluz L, Chapman DP, Moriarty DG, Owens M, Mokdad AH. Risk behaviors and healthcare coverage among adults by frequent mental distress status, 2001. Am J Prev Med 2004;26(3):213-6. CrossRef 圈 PubMed 国

29. Rothman KJ, Greenland S, Lash TL. Measures of effect and measures of association. In: Modern epidemiology. Philadelphia (PA): Lippincott Williams \& Wilkins; 2008.

30. Van de Mheen HD, Stronks K, Mackenbach JP. A life course perspective on socio-economic inequalities in health: the influence of childhood socio-economic conditions as selection process. Sociol Health Illn 1998;20(5):754-77. CrossRef 圈

31. Baron RM, Kenny DA. The moderator-mediator distinction in social psychological research: conceptual, strategic, and statistical considerations. J Pers Soc Psychol 1986;51(6):1173-82. CrossRef 圈 PubMed 圈

32. Research Triangle Institute. SUDAAN, release 10.0. Research Triangle Park (NC): 2008.

33. Cutts DB, Meyers AF, Black MM, Casey PH, Chilton M, Cook JT, et al. US housing insecurity and the health of very young children. Am J Public Health 2011;101(8):1508-14. CrossRef 国 PubMed 圈

34. Wolfersteig WL, Lewis H, Musgrave T, Johnson T, Wolven T, Marsiglia FF. Arizona health survey: food, housing insecurity and health. Phoenix (AZ): Arizona State University, Southwest Interdisciplinary Research Center; 2011.

35. Polivy J. Psychological consequences of food restriction. J Am Diet Assoc 1996;96(6):589-92. CrossRef 橉 PubMed 圈

36. Singh GK, Kenney MK. Rising prevalence and neighborhood, social, and behavioral determinants of sleep problems in US children and adolescents, 2003-2012. Sleep Disord 2013;2013:394320. CrossRef 国 PubMed 国

37. Krieger J, Higgins DL. Housing and health: time again for public health action. Am J Public Health 2002;92 (5):758-68. CrossRef 圈 PubMed 圈

38. Ekstedt M, Akerstedt T, Soderstrom M. Microarousals during sleep are associated with increased levels of lipids,

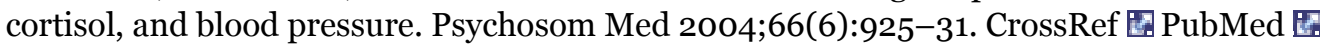

39. Born J, Hansen K, Marshall L, Molle M, Fehm HL. Timing the end of nocturnal sleep. Nature 1999;397(6714):2930. CrossRef 圈 PubMed 圈

40. Friess E, Windermann K, Steiger A, Holsboer F. The hypothalamic-pituitary-adrenocortical system and sleep in

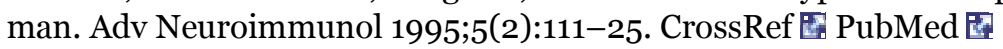


Preventing Chronic Disease | Relationships Between Housing and Food Insecurity, Frequ... Page 7 of 9

41. Harvey AG, Tang NK, Browning L. Cognitive approaches to insomnia. Clin Psychol Rev 2005;25(5):593-611. CrossRef 国 PubMed 圈

42. Troxel WM, Buysse DJ, Matthews KA, Kravitz HM, Bromberge JT, Sowers M, et al. Marital/cohabitation status and history in relation to sleep in midlife women. Sleep 2010;33(7):973-81. PubMed 国

\section{Tables}

Table 1. Distribution of Selected Characteristics Among Adults 18 Years or Older in 12 US States, a 2009

\begin{tabular}{|c|c|c|}
\hline Characteristic & $\mathbf{N b}$ & $\%$ (95\% Confidence Interval)c \\
\hline Total & 68,111 & 100.0 \\
\hline \multicolumn{3}{|l|}{ Sex } \\
\hline Male & 25,739 & $48.8(47.8-49.7)$ \\
\hline Female & 42,372 & $51.2(50.3-52.2)$ \\
\hline \multicolumn{3}{|l|}{ Age, $y$} \\
\hline $18-44$ & 17,309 & $49.2(48.2-50.1)$ \\
\hline $45-64$ & 29,203 & $34.4(33.6-35.2)$ \\
\hline$\geq 65$ & 21,259 & $16.4(15.9-16.9)$ \\
\hline \multicolumn{3}{|l|}{ Race/ethnicity } \\
\hline Non-Hispanic white & 48,802 & $62.2(61.1-63.2)$ \\
\hline Non-Hispanic black & 7,265 & $9.2(8.7-9.7)$ \\
\hline Hispanic & 4,477 & $19.2(18.1-20.2)$ \\
\hline Other & 7,007 & $9.5(8.9-10.1)$ \\
\hline \multicolumn{3}{|l|}{ Education, y } \\
\hline$<12$ & 6,377 & $11.6(10.9-12.4)$ \\
\hline 12 & 20,257 & $26.5(25.7-27.3)$ \\
\hline$>12$ & 41,395 & $61.9(60.9-62.8)$ \\
\hline Housing insecurityd & 14,334 & $28.5(27.6-29.5)$ \\
\hline Food insecuritye & 12,166 & $19.3(18.5-20.2)$ \\
\hline Frequent mental distressf & 6,965 & $10.8(10.2-11.4)$ \\
\hline Frequent insufficient sleepg & 16,238 & $26.4(25.6-27.2)$ \\
\hline
\end{tabular}

a Adult population was drawn from respondents to an optional module from the 2009 Behavioral Risk Factor Surveillance System in 12 states (Alabama, Arkansas, California, Hawaii, Illinois, Kansas, Louisiana, Nebraska, New Mexico, Oklahoma, South Carolina, and Wisconsin).

b Unweighted sample size.

c Weighted percentage and 95\% confidence interval.

d Housing insecurity was defined as a response of "always," "usually," or "sometimes" felt worried or stressed about having enough money to pay rent or mortgage.

e Food insecurity was defined as a response of "always," "usually," or "sometimes" felt worried or stressed about having enough money to buy nutritious meals.

f Frequent mental distress was defined as a response of $\geq 14$ days that mental health was not good in the past 30 days.

$g$ Frequent insufficient sleep was defined as a response of $\geq 14$ days of not getting enough rest/sleep in the past 30 days. 
Preventing Chronic Disease | Relationships Between Housing and Food Insecurity, Frequ... Page 8 of 9

Table 2. Prevalencea of Frequent Insufficient Sleepb and Frequent Mental Distressc Among Adults 18 Years or Older in 12 US States,d 2009

\begin{tabular}{|c|c|c|c|c|}
\hline Characteristic & $\begin{array}{c}\text { Frequent Insufficient Sleep, \% } \\
(95 \% \mathrm{CI})\end{array}$ & P Valuee & $\begin{array}{c}\text { Frequent Mental Distress, \% } \\
(95 \% \mathrm{CI})\end{array}$ & $P$ Valuee \\
\hline \multicolumn{5}{|l|}{ Sex } \\
\hline Men & $23.9(22.6-25.2)$ & $\begin{array}{r}1 \\
\text { [Reference] }\end{array}$ & $8.8(7.9-9.7)$ & $\begin{array}{r}1 \\
\text { [Reference }]\end{array}$ \\
\hline Women & $28.8(27.8-29.8)$ & $<.001$ & $12.6(11.8-13.4)$ & $<.001$ \\
\hline \multicolumn{5}{|l|}{ Age, y } \\
\hline $18-44$ & $30.7(29.3-32.2)$ & $<.001$ & $11.1(10.1-12.1)$ & $<.001$ \\
\hline $45-64$ & $26.1(25.0-27.3)$ & $<.001$ & $12.0(11.1-12.9)$ & $<.001$ \\
\hline$\geq 65$ & $14.1(13.1-15.1)$ & $\begin{array}{r}1 \\
\text { [Reference] }\end{array}$ & $7.3(6.3-8.2)$ & $\begin{array}{r}1 \\
\text { [Reference] }\end{array}$ \\
\hline \multicolumn{5}{|l|}{ Race/ethnicity } \\
\hline $\begin{array}{l}\text { Non-Hispanic } \\
\text { white }\end{array}$ & $26.5(25.6-27.3)$ & $\begin{array}{r}1 \\
\text { [Reference] }\end{array}$ & $9.6(9.0-10.1)$ & $\begin{array}{r}1 \\
\text { [Reference }]\end{array}$ \\
\hline $\begin{array}{l}\text { Non-Hispanic } \\
\text { black }\end{array}$ & $29.4(27.0-31.9)$ & .02 & $14.8(12.5-17.1)$ & $<.001$ \\
\hline Hispanic & $24.5(21.8-27.1)$ & .17 & $13.5(11.3-15.6)$ & $<.001$ \\
\hline Other & $27.1(24.0-30.2)$ & .69 & $9.2(7.5-11.0)$ & .71 \\
\hline \multicolumn{5}{|l|}{ Education, y } \\
\hline$<12$ & $26.1(23.2-28.9)$ & .84 & $16.3(14.0-18.6)$ & $<.001$ \\
\hline 12 & $26.6(25.0-28.2)$ & .81 & $12.6(11.3-14.0)$ & $<.001$ \\
\hline$>12$ & $26.4(25.4-27.4)$ & $\begin{array}{r}1 \\
\text { [Reference] }\end{array}$ & $9.0(8.3-9.6)$ & $\begin{array}{r}1 \\
\text { [Reference }]\end{array}$ \\
\hline \multicolumn{5}{|c|}{ Housing insecurityf } \\
\hline No & $21.6(20.7-22.5)$ & $\begin{array}{r}1 \\
\text { [Reference] }\end{array}$ & $6.8(6.2-7.4)$ & $\begin{array}{r}1 \\
\text { [Reference }]\end{array}$ \\
\hline Yes & $37.7(35.7-39.6)$ & $<.001$ & $20.1(18.5-21.7)$ & $<.001$ \\
\hline \multicolumn{5}{|c|}{ Food insecurityg } \\
\hline No & $22.9(22.1-23.7)$ & $\begin{array}{r}1 \\
\text { [Reference] }\end{array}$ & $7.7(7.1-8.3)$ & $\begin{array}{r}1 \\
\text { [Reference }]\end{array}$ \\
\hline Yes & $41.1(38.7-43.4)$ & $<.001$ & $23.5(21.7-25.3)$ & $<.001$ \\
\hline \multicolumn{5}{|c|}{ Frequent mental distress ( $\geq 14 \mathrm{~d} / 30 \mathrm{~d}$ ) } \\
\hline No & $22.3(21.5-23.1)$ & $\begin{array}{r}1 \\
\text { [Reference] }\end{array}$ & & - \\
\hline Yes & $59.7(56.7-62.7)$ & $<.001$ & & - \\
\hline \multicolumn{5}{|c|}{ Frequent insufficient sleep $(\geq 14 d / 30 d)$} \\
\hline No & & - & $5.9(5.3-6.5)$ & $\begin{array}{r}1 \\
\text { [Reference }]\end{array}$ \\
\hline Yes & & - & $24.4(22.9-26.0)$ & $<.001$ \\
\hline
\end{tabular}

Abbreviations: CI, confidence interval; -, does not apply.

a Prevalence (\%) and $95 \%$ CI were weighted to take study design into account.

b Frequent insufficient sleep was defined as a response of $\geq 14$ days of not getting enough rest/sleep in the past 30 days.

c Frequent mental distress was defined as a response of $\geq 14$ days that mental health was not good in the past 30 days.

d Adult population was drawn from respondents to an optional module from the 2009 Behavioral Risk Factor Surveillance 
Preventing Chronic Disease | Relationships Between Housing and Food Insecurity, Frequ... Page 9 of 9

System in 12 states (Alabama, Arkansas, California, Hawaii, Illinois, Kansas, Louisiana, Nebraska, New Mexico, Oklahoma, South Carolina, and Wisconsin).

e Obtained from a 2-sided $t$ test to assess the difference of prevalence of frequent insufficient sleep and frequent mental distress among groups.

f Housing insecurity was defined as a response of "always," "usually," or "sometimes" felt worried or stressed about having enough money to pay rent or mortgage.

g Food insecurity was defined as a response of "always," "usually," or "sometimes" felt worried or stressed about having enough money to buy nutritious meals.

Table 3. Prevalence Ratio and 95\% Confidence Interval of Frequent Insufficient Sleep, by Housing Insecurity and Food Insecurity Among Adults 18 Years or Older in 12 US States, a 2009

\begin{tabular}{|l|r|r|r|}
\hline Characteristic & \multicolumn{1}{c|}{ Model 1b } & \multicolumn{1}{c|}{ Model 2c } \\
\hline Housing insecurity \\
\hline No & 1 [Reference] & 1 [Reference] & 1 [Reference] \\
\hline Yes & $1.74(1.63-1.86)$ & $1.67(1.55-1.79)$ & $1.49(1.38-1.60) \mathrm{e}$ \\
\hline Food insecurity & 1 [Reference] & $1[$ Reference] & 1 [Reference] \\
\hline No & $1.79(1.68-1.92)$ & $1.75(1.62-1.88)$ & $1.54(1.42-1.67) \mathrm{e}$ \\
\hline Yes &
\end{tabular}

a Adults were drawn from respondents to an optional module from the 2009 Behavioral Risk Factor Surveillance System in 12 states (Alabama, Arkansas, California, Hawaii, Illinois, Kansas, Louisiana, Nebraska, New Mexico, Oklahoma, South Carolina, and Wisconsin).

b Model 1: obtained from separate univariate logistic regression models that included only insecurity variables.

c Model 2: results adjusted for age, sex, race/ethnicity, and education.

d Model 3: results adjusted for all covariates in model 2 and for frequent mental distress.

e $20 \%$ to less than $40 \%$ reduction of prevalence ratio between model with and without the potential mediator.

The opinions expressed by authors contributing to this journal do not necessarily reflect the opinions of the U.S. Department of Health and Human Services, the Public Health Service, the Centers for Disease Control and Prevention, or the authors' affiliated institutions.

For Questions About This Article Contact pcdeditor@cdc.gov

Page last reviewed: March 13, 2014

Page last updated: March 13, 2014

Content source: National Center for Chronic Disease Prevention and Health Promotion

Centers for Disease Control and Prevention 1600 Clifton Rd. Atlanta, GA 30333, USA

800-CDC-INFO (80o-232-4636) TTY: (888) 232-6348 - Contact CDC-INFO

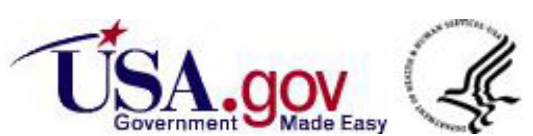

